OPEN ACCESS

Edited by:

Fabienne Brilot,

University of Sydney, Australia

Reviewed by:

Ulises Gomez-Pinedo,

Instituto de Investigación Sanitaria del

Hospital Clínico San Carlos, Spain

Margherita Nosadini,

University of Padova, Italy

Ming Lim,

Guy's and St Thomas' NHS

Foundation Trust, United Kingdom

*Correspondence:

Zhengqi Lu

Izq1828@outlook.com

tThese authors have contributed equally to this work

Specialty section: This article was submitted to

Multiple Sclerosis and

Neuroimmunology,

a section of the journal

Frontiers in Neurology

Received: 08 October 2019

Accepted: 03 February 2020

Published: 28 February 2020

Citation:

Zhang $B$, Yang $Y$, Lin Y, Ai L, Men X and Lu $Z$ (2020) Serum Systemic

Autoantibodies in

Anti-N-Methyl-D-Aspartate Receptor

Encephalitis. Front. Neurol. 11:117.

doi: 10.3389/fneur.2020.00117

\section{Serum Systemic Autoantibodies in Anti-N-Methyl-D-Aspartate Receptor Encephalitis}

\author{
Bingjun Zhang ${ }^{\dagger}$, Yu Yang ${ }^{\dagger}$, Yinyao Lin ${ }^{\dagger}$, Lulu Ai, Xuejiao Men and Zhengqi Lu* \\ Department of Neurology, The Third Affiliated Hospital of Sun Yat-sen University, Guangzhou, China
}

Objective: The aim of this retrospective study was to investigate the relationship between serum systemic autoantibodies and anti-N-methyl-D-aspartate receptor (NMDAR) encephalitis.

Methods: Thirty-nine patients with anti-NMDAR encephalitis were examined for serum systemic autoantibodies (antinuclear antibodies, extractable nuclear antigen autoantibodies, rheumatoid factors, and anti-neutrophil cytoplasmic antibodies), in comparison with 39 neuromyelitis optica spectrum disorder (NMOSD) and 78 healthy controls. Clinical features, cerebrospinal fluid characteristics, and outcomes were compared between the two subgroups of anti-NMDAR patients with positive and negative systemic autoantibodies, respectively.

Results: Anti-NMDAR encephalitis patients had higher frequency of positive serum systemic autoantibodies than healthy controls (23.1 vs. $2.6 \%, p=0.001)$ and lower frequency than NMOSD (23.1 vs. 48.7\%, $p=0.018$ ). No patients were diagnosed comorbidities with non-organ-specific autoimmune diseases. Consciousness disturbance was more frequent in autoantibodies positive group than in the negative group (88.9 vs. $40.0 \%, p=0.02$ ). Autoantibody positive group had a poorer outcome than autoantibody negative group (55.6 vs. $86.7 \%, p=0.043$ ). There was a negative correlation between serum autoantibodies and outcomes in anti-NMDAR encephalitis patients ( $r=-0.325, p=0.044)$.

Conclusion: Our data demonstrated serum systemic autoantibodies were more frequent in anti-NMDAR encephalitis patients than in healthy controls and less frequent than NMOSD, which were associated with higher severity of disease.

Keywords: anti-N-methyl-D-aspartate receptor encephalitis, systemic autoantibodies, outcome, modified rankin scale, autoimmune diseases

\section{INTRODUCTION}

Anti-N-methyl-D-aspartate receptor (NMDAR) encephalitis is the most common autoimmune encephalitis (AE) related to antibody-mediated synaptic dysfunction, which is characterized by the subacute development of psychosis, epileptic seizures, memory deficit, autonomic instability, and a decrease in the level of consciousness (1). The disease can be triggered by NMDAR-expressing ovarian teratomas or occur secondarily to virus encephalitis, while the initiating events remain unclear in most cases (2-4). 
Previous reports have demonstrated the intertwining relationships between systemic immune abnormalities and immune-mediated neurological disorders, such as neuromyelitis optica spectrum disorder (NMOSD), and multiple sclerosis $(5,6)$. Recently, several studies have revealed anti-thyroid antibodies abnormalities and elevated complement levels are frequent in patients with anti-NMDAR encephalitis, which are associated with the outcomes (7-9). Serum systemic autoantibodies that are indicative of systemic immune diseases, such as antinuclear antibodies (ANAs), extractable nuclear antigen autoantibodies (ENAs), rheumatoid factors (RFs), and anti-neutrophil cytoplasmic antibodies (ANCAs), have also been detected in patients with $\mathrm{AE}$, but the literature in this regard is limited $(8,10)$. However, the association between systemic autoantibodies and anti-NMDAR encephalitis has not been discussed.

Therefore, this study aims to analyze serum systemic autoantibodies in patients with anti-NMDAR encephalitis, and determine the association with clinical characteristics in the patients.

\section{METHODS}

\section{Patients and Controls}

This retrospective study enrolled 39 patients with anti-NMDAR encephalitis who were admitted to the Third Affiliated Hospital of Sun Yat-sen University from February 2016 to December 2017. Anti-NMDAR encephalitis was defined according to diagnostic criteria (11). A commercial indirect fluorescence assay (EUROIMMUN, Medizinische Labordiagnostika, Lubeck, Germany) was used to screen for IgG antibody to the NMDAR (9). The disease control group included 39 NMOSD patients who were defined according to diagnostic criteria (12). The healthy control group included 78 individuals who visited the health examination center at our hospital for health examination. The additional data of healthy control group was shown in Supplementary Material.

Gender, age, clinical manifestations, time from onset to hospitalization, length of hospital stay, and length of followup were recorded. Examinations including brain magnetic resonance imaging (MRI) and cerebrospinal fluid (CSF) were reviewed. The patients received first-line immunotherapy [steroids and intravenous immunoglobulin (IVIg) with or without plasma exchange], second-line immunotherapy (rituximab with or without cyclophosphamide). The patients' neurological function and outcome were evaluated using the modified Rankin Scale (mRS) at admission and at discharge.

\section{Autoantibodies Analysis in Serum}

Systemic autoantibodies (ANAs, ENAs, RFs, ANCAs) tests were measured on Tenfly Phoenix Auto Blot Analyzer (YHLO, Shenzhen, China) at the clinical rheumatology immunology laboratory of the Third Affiliated Hospital of Sun Yat-sen University (6). The samples were collected at admission (prior to immune treatment), at discharge, and the last follow-up.

\section{Statistical Analysis}

All quantitative data in this study are presented as mean \pm standard deviation (SD) or median (range). Quantitative data were processed using the Mann-Whitney U-test or Student's $t$ test. Qualitative data were analyzed with the $\chi^{2}$ test or Fisher's exact test. The relationship of two variables was analyzed using Spearman's rank test. Values of $p<0.05$ were considered statistically significant. Statistical analysis was performed by SPSS version 22.0 (SPSS Inc., Chicago, IL, USA).

\section{RESULTS}

\section{Demographic and Clinical Features}

Baseline characteristics were presented in Table 1. A total of 39 patients with anti-NMDAR encephalitis (age, $27.7 \pm 12.7$ years; female: male, 19:20), 39 patients with NMOSD (age, $41.1 \pm 13.8$ years; female: male, $36: 3$ ), and 78 controls (age, $30.3 \pm 12.2$ years; female: male, 41:37) were enrolled in our study. Ten patients (25.6\%) had ovarian teratoma. Other tumors were not detected. As for the clinical manifestation at onset, 21 patients $(53.8 \%)$ had epileptic seizures, 29 patients $(74.4 \%)$ had behavioral and psychiatric disturbances, 20 patients (51.3\%) had consciousness disturbance, 9 patients $(23.1 \%)$ had short-term memory deficits. Fourteen patients (35.9\%) had abnormal MRI findings, and 25 patients $(64.1 \%)$ had abnormal CSF findings. The median anti-NMDAR antibodies titer in CSF is $1: 64$ (1:1-1:320). On admission, the median mRS score which used to evaluate the severity of anti-NMDAR encephalitis was 4 (range 1-5). 24 patients $(61.5 \%)$ received first-line treatment and 15 patients (38.5\%) received first-line and second-line immunotherapy. 31 patients $(79.5 \%)$ had a good outcome $(\mathrm{mRS}<2)$ at discharge. Serum systemic autoantibodies were more frequent in antiNMDAR encephalitis patients than in healthy controls (23.1 vs. $2.6 \%, p=0.001)$, which less frequent in anti-NMDAR encephalitis patients than in NMOSD (23.1 vs. $48.7 \%, p=0.018$ ).

\section{Clinical Characteristics in Serum Autoantibodies Positive Patients With Anti-NMDAR Encephalitis}

As shown in Table 2, 9 patients (age, $30.0 \pm 16.2$ years; female: male, 6:3) had positive serum autoantibodies, including 7 ANA positive, 1 ANCA positive, and 1 centromere antibody positive. However, no patients were diagnosed comorbidities with non-organ-specific autoimmune diseases [e.g., lupus, sjögren syndrome (SS), rheumatoid arthritis (RA)]. After treatment, 7 patients $(77.8 \%)$ serum autoantibodies turn to negative at discharge. The serum autoantibodies results of all anti-NMDAR encephalitis patients had no alteration from discharge to the last follow-up.

\section{Clinical Characteristics Between Serum Autoantibodies Positive and Negative Patients With Anti-NMDAR Encephalitis}

As shown in Table 3, there were no statistical differences in gender and age between serum autoantibodies positive and negative patients with anti-NMDAR encephalitis $(p>0.05)$. 
TABLE 1 | Demographic features of anti-NMDAR encephalitis patients and controls.

\begin{tabular}{|c|c|c|c|c|c|c|}
\hline Characteristics & $\begin{array}{c}\text { Anti-NMDAR } \\
\text { encephalitis }(n=39)\end{array}$ & NMOSD $(n=39)$ & Healthy control $(n=78)$ & p1 & p2 & p3 \\
\hline $\mathrm{F} / \mathrm{M}$ & 19:20 & $36: 3$ & $41: 37$ & $<0.001$ & 0.695 & $<0.001$ \\
\hline Age (mean $\pm \mathrm{SD}$, years) & $27.7 \pm 12.7$ & $41.1 \pm 13.8$ & $30.3 \pm 12.2$ & $<0.001$ & 0.286 & $<0.001$ \\
\hline Patients with ovarian teratoma, $n(\%)$ & $10(25.6)$ & & & & & \\
\hline \multicolumn{7}{|l|}{ Clinical presentation at onset, $n(\%)$} \\
\hline Epileptic seizures & $21(53.8)$ & & & & & \\
\hline $\begin{array}{l}\text { Behavioral and psychiatric } \\
\text { disturbances }\end{array}$ & $29(74.4)$ & & & & & \\
\hline Consciousness disturbance & $20(51.3)$ & & & & & \\
\hline Short-term memory deficits & $9(23.1)$ & & & & & \\
\hline Brain lesions on MRI, $n(\%)$ & $14(35.9)$ & & & & & \\
\hline CSF abnormalities, $n(\%)$ & $25(64.1)$ & & & & & \\
\hline $\begin{array}{l}\text { CSF NMDAR antibody, median } \\
\text { (range) }\end{array}$ & $1: 64(1: 1-1: 320)$ & & & & & \\
\hline Serum systemic autoantibodies, $n$ (\%) & $9(23.1)$ & $19(48.7)$ & $2(2.6)$ & 0.018 & 0.001 & $<0.001$ \\
\hline mRS on admission, median (range) & $4(1-5)$ & & & & & \\
\hline $\mathrm{mRS}<2$ at discharge, $n(\%)$ & $31(79.5)$ & & & & & \\
\hline First-line treatment, $n(\%)$ & $24(61.5)$ & & & & & \\
\hline $\begin{array}{l}\text { First-line combined with second-line } \\
\text { treatment, } n(\%)\end{array}$ & $15(38.5)$ & & & & & \\
\hline
\end{tabular}

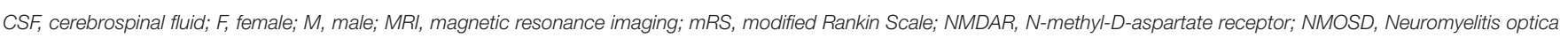
spectrum disorder; $S D$, standard deviation.

p1, anti-NMDAR encephalitis vs. NMOSD; p2, anti-NMDAR encephalitis vs. healthy control; p3, NMOSD vs. healthy control.

TABLE 2 | Clinical characteristics in anti-NMDAR encephalitis patients with serum autoantibodies positive.

\begin{tabular}{|c|c|c|c|c|c|c|}
\hline Patients & Gender & Age, years & Systemic autoantibodies & Turn negative & Good outcomes & CSF NMDAR antibody \\
\hline 1 & $\mathrm{~F}$ & 22 & ANA $(1: 100)$ & Yes & Yes & $1: 100$ \\
\hline 2 & M & 10 & ANA (1: 100) & No & No & $1: 1$ \\
\hline 3 & $\mathrm{~F}$ & 50 & ANA $(1: 100)$ & Yes & Yes & $1: 32$ \\
\hline 4 & $\mathrm{~F}$ & 33 & ANA $(1: 100)$ & No & No & $1: 320$ \\
\hline 5 & $\mathrm{~F}$ & 31 & ANA $(1: 100)$ & Yes & Yes & $1: 32$ \\
\hline 6 & M & 32 & ANA (1:100) & Yes & No & $1: 64$ \\
\hline 7 & $\mathrm{~F}$ & 13 & ANA (1:100) & Yes & Yes & $1: 10$ \\
\hline 8 & M & 20 & ANCA (1:100) & Yes & Yes & $1: 32$ \\
\hline 9 & $\mathrm{~F}$ & 59 & Centromere antibody (1:100) & Yes & No & $1: 320$ \\
\hline
\end{tabular}

ANA, antinuclear antibody; ANCA, anti-neutrophil cytoplasmic antibody; CSF, cerebrospinal fluid; F, female; M, male; NMDAR, N-methyl-D-aspartate receptor.

However, consciousness disturbance was more frequent in autoantibodies positive group than in the negative group (88.9 vs. $40.0 \%, p=0.02$ ). No difference was found in MRI findings (Table 4), CSF abnormalities, CSF anti-NMDAR antibodies titers, mRS on admission, time from onset to hospitalization, length of hospital stay, length of follow-up, and immune treatment between two groups $(p>0.05)$. Autoantibody positive group had a poorer outcome than autoantibody negative group (55.6 vs. $86.7 \%, p=0.043$ ) (Figure 1). The relationship between serum autoantibodies and outcome in patients with anti-NMDAR encephalitis was evaluated. There was a negative correlation between serum autoantibodies and outcome in antiNMDAR encephalitis patients $(r=-0.325, p=0.044)$.

\section{DISCUSSION}

In the present study, we found that anti-NMDAR encephalitis patients had higher frequency of positive serum systemic autoantibodies than healthy controls and lower frequency than NMOSD. We also found ANA was the most common serum autoantibodies in anti-NMDAR encephalitis. However, no patients were diagnosed comorbidities with non-organspecific autoimmune diseases. Furthermore, good outcomes in anti-NMDAR encephalitis patients were significantly negatively associated with the serum autoantibodies. To the best of our knowledge, this is the first study to analyze serum systemic autoantibodies in patients with anti-NMDAR encephalitis. 
TABLE 3 | Comparison of clinical features in patients with anti-NMDAR encephalitis based on serum systemic autoantibodies status.

\begin{tabular}{|c|c|c|c|}
\hline Characteristics & $\begin{array}{c}\text { Serum } \\
\text { autoantibodies } \\
\text { positive }(n=9)\end{array}$ & $\begin{array}{c}\text { Serum } \\
\text { autoantibodies } \\
\text { negative }(n=30)\end{array}$ & $p$ \\
\hline F/M & $6: 3$ & 13: 17 & 0.273 \\
\hline $\begin{array}{l}\text { Age (mean } \pm \mathrm{SD} \text {, } \\
\text { years) }\end{array}$ & $30.0 \pm 16.2$ & $27.0 \pm 11.7$ & 0.538 \\
\hline $\begin{array}{l}\text { Patients with } \\
\text { ovarian teratoma, } \\
n(\%)\end{array}$ & $4(44.4)$ & $6(20.0)$ & 0.299 \\
\hline \multicolumn{4}{|l|}{$\begin{array}{l}\text { Clinical } \\
\text { presentation at } \\
\text { onset, } n(\%)\end{array}$} \\
\hline Epileptic seizures & $6(66.7)$ & $15(50)$ & 0.464 \\
\hline $\begin{array}{l}\text { Behavioral and } \\
\text { psychiatric } \\
\text { disturbances }\end{array}$ & $7(77.8)$ & $22(73.3)$ & 1 \\
\hline $\begin{array}{l}\text { Consciousness } \\
\text { disturbance }\end{array}$ & 8 (88.9) & $12(40)$ & 0.02 \\
\hline $\begin{array}{l}\text { Short-term } \\
\text { memory deficits }\end{array}$ & $1(11.1)$ & $8(26.7)$ & 0.654 \\
\hline $\begin{array}{l}\text { Brain lesions on } \\
\mathrm{MRl}, n(\%)\end{array}$ & 3 (33.3) & $11(36.7)$ & 0.855 \\
\hline $\begin{array}{l}\text { CSF abnormalities, } \\
n(\%)\end{array}$ & 7 (77.8) & $18(60.0)$ & 0.445 \\
\hline $\begin{array}{l}\text { CSF NMDAR } \\
\text { antibody, median } \\
\text { (range) }\end{array}$ & $1: 32(1: 1-1: 320)$ & $1: 64(1: 10-1: 320)$ & 0.476 \\
\hline $\begin{array}{l}\text { mRS on } \\
\text { admission, median } \\
\text { (range) }\end{array}$ & $4(1-5)$ & $4(1-5)$ & 0.48 \\
\hline $\begin{array}{l}\text { Time from onset to } \\
\text { hospitalization, } \\
\text { days }\end{array}$ & $20(1-60)$ & $15(4-120)$ & 0.611 \\
\hline $\begin{array}{l}\text { Length of hospital } \\
\text { stay, days }\end{array}$ & $26(15-84)$ & $26(10-108)$ & 0.987 \\
\hline $\begin{array}{l}\mathrm{mRS}<2 \text { at } \\
\text { discharge, } n(\%)\end{array}$ & $5(55.6)$ & $26(86.7)$ & 0.043 \\
\hline $\begin{array}{l}\text { First-line } \\
\text { treatment, } n(\%)\end{array}$ & $5(55.6)$ & 19 (63.3) & 0.711 \\
\hline $\begin{array}{l}\text { First-line } \\
\text { combined with } \\
\text { second-line } \\
\text { treatment, } n(\%)\end{array}$ & $4(44.4)$ & $11(36.7)$ & 0.711 \\
\hline Follow-up, months & $8(3-48)$ & $10(3-48)$ & 0.588 \\
\hline $\begin{array}{l}\text { Follow-up CSF } \\
\text { NMDAR antibody, } \\
\text { median (range) }\end{array}$ & $1: 10(0-1: 10)$ & $1: 1(0-1: 100)$ & 0.883 \\
\hline
\end{tabular}

CSF, cerebrospinal fluid; F, female; $M$, male; MRI, magnetic resonance imaging; $m R S$, modified Rankin Scale; NMDAR, N-methyl-D-aspartate receptor; $S D$, standard deviation.

Autoantibodies are the result of a failure of the immune system to discriminate between "self" and "non-self," which target a person's own antigen (13). Autoantibodies cause inflammation, damage, and/or dysfunction of organs, resulting in autoimmune disorders. Disorders due to systemic autoantibodies, which include ANAs, ENAs, RFs, and ANCAs, affect multiple organs or systems. Several previous reports
TABLE 4 | Comparison of MRI features in patients with anti-NMDAR encephalitis based on serum systemic autoantibodies status.

\begin{tabular}{lccc}
\hline $\begin{array}{l}\text { Characteristics, } \\
\boldsymbol{n}(\%)\end{array}$ & $\begin{array}{c}\text { Serum } \\
\text { autoantibodies } \\
\text { positive }(\boldsymbol{n}=\mathbf{9})\end{array}$ & $\begin{array}{c}\text { Serum } \\
\text { autoantibodies } \\
\text { negative }(\boldsymbol{n}=\mathbf{3 0})\end{array}$ & $\boldsymbol{p}$ \\
\hline Limbic system & $2(22.2)$ & $4(13.3)$ & 0.903 \\
Brain lobes & $3(33.3)$ & $5(16.7)$ & 0.538 \\
White Matter & $1(11.1)$ & $1(3.3)$ & 0.947 \\
Basal ganglia & $1(11.1)$ & 0 & 0.517 \\
Brainstem & $1(11.1)$ & $1(3.3)$ & 0.947 \\
Cerebellum & $1(11.1)$ & $1(3.3)$ & 0.947 \\
\hline
\end{tabular}

$M R I$, magnetic resonance imaging; NMDAR, $N$-methyl-D-aspartate receptor.

have found the idiopathic inflammatory demyelinating diseases have positive systemic autoantibodies and comorbidities with systemic autoimmune disorders $(5,14)$. In our previous study, we found $25.8 \%$ NMOSD comorbidities with systemic or organspecific autoimmune disorders (6). Half of NMOSD have ANA or Anti-SS-related antigen A antibody positive in the serum. Recently, anti-thyroid antibodies abnormalities and elevated complement levels are frequent in patients with anti-NMDAR encephalitis, which are associated with the short-term prognosis (7-9). Furthermore, in our present study, only 9 in 39 of anti-NMDAR encephalitis were positive for serum systemic autoantibodies (7 ANA, 1 ANCA, and 1 centromere antibody). However, the titers of serum systemic autoantibodies were low in the patients. There were no patients diagnosed comorbidities with systemic autoimmune diseases. Our results have some different from the recent paper conducted by Zhao et al., which found anti-NMDAR encephalitis can coexist with non-organspecific autoimmune diseases, such as lupus (15). The paper also found that autoimmune diseases were more frequent in anti-leucine-rich glioma-inactivated 1 encephalitis than in antiNMDAR encephalitis, and that autoimmune comorbidities did not affect the clinical course of AE. The prevalence of the most common type of autoantibody in the anti-NMDAR encephalitis, ANA, may be positive with a variety of autoimmune diseases, including lupus, SS, RA, and autoimmune hepatitis, and many non-autoimmune factors, such as tumors, infectious diseases, and pharmaceuticals $(16,17)$. Also, an ANA positive frequency of $2-20 \%$ in healthy individuals has been reported (18-20). In the present study, healthy control showed a relatively low frequency of $2.6 \%$ for positive systemic autoantibodies. Furthermore, antiNMDAR encephalitis patients had higher frequency of serum autoantibodies than healthy controls. Autoimmune disease is caused by a complex genetic predisposition that is attributable to multiple genetic variants and human leukocyte antigen (HLA) alleles $(21,22)$. The phenomenons are not rare that one autoimmune disease increases the chance of an additional autoimmune disease, and that autoimmune disease patient has multiple positive antibodies. Recent studies have shown that anti-NMDAR encephalitis was associated with the HLA alleles $(23,24)$. Perhaps, genetic predisposition is the important reason for the increased prevalence of systemic autoantibodies in patients with anti-NMDAR encephalitis. 


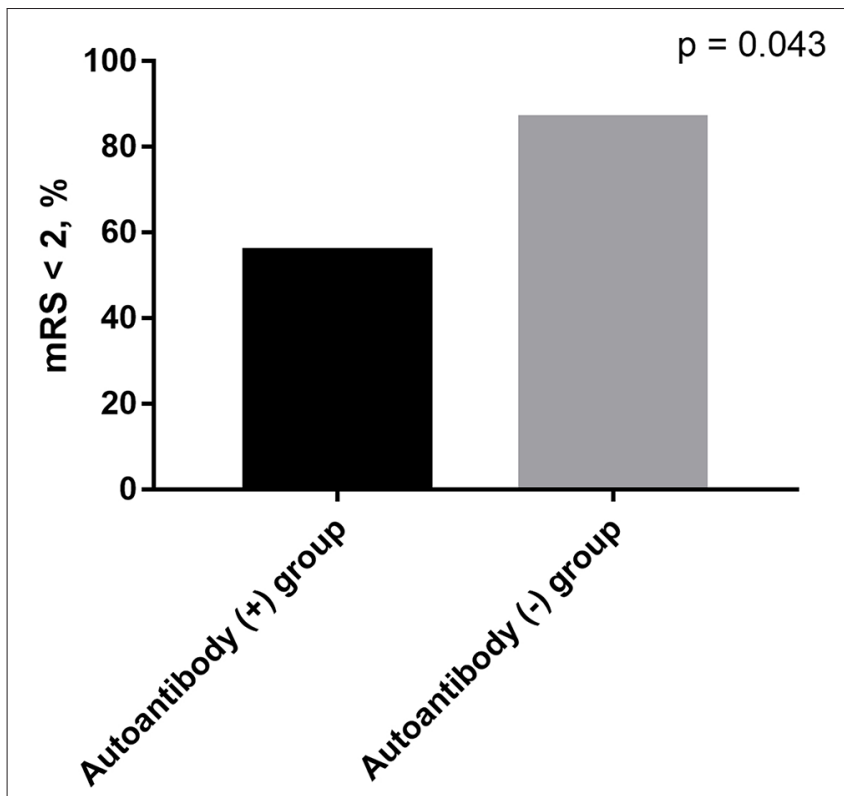

FIGURE 1 | The outcomes in anti-NMDAR encephalitis patients. Autoantibody positive group had a poorer outcome than autoantibody negative group (55.6 vs. $86.7 \%, p=0.043)$.

This study also compared the characteristics of anti-NMDAR encephalitis patients according to serum systemic autoantibodies status. In our study, more than one half of anti-NMDAR encephalitis patients had consciousness disturbance. And a study conducted by Lin et al. showed that consciousness disturbance is typically severe syndrome (7), which is consistent with our result. However, we found consciousness disturbance was more frequent in autoantibodies positive group than in negative group. Interestingly, there was a negative correlation between serum autoantibodies and outcome in anti-NMDAR encephalitis patients. It is easy for us to find a direct phenomenon in autoantibodies positive group: severe syndrome, bad outcome. The reasons for this are still unknown. One of the reasons is due to the profound derangement of the immune system in these severe patients with systemic autoantibodies. Positive systemic autoantibodies were detected in the CSF in neuropsychiatric lupus patients, which played important role in the disruption of blood brain barrier (BBB) (25-27). Recent studies have suggested the integrity of $\mathrm{BBB}$ was impaired in anti-NMDAR antibody positive patients $(28,29)$. Although systemic autoantibodies were not tested in the CSF in our study, it is thus tempting to speculate that serum systemic autoantibodies play a role in the damages of neurons by interacting with anti-NMDAR antibody against neuronal surface antigens, where they can access the brain because of BBB disruption. The synergistic effect between systemic autoantibodies and anti-NMDAR antibody might cause more severe symptoms, such as consciousness disturbance which resulted in higher mRS score.

Anti-NMDAR encephalitis is a treatable and even curable disease. In our present study, nearly $80 \%$ had good outcome $(\mathrm{mRS}<2)$ at discharge, which is consistent with previous researches $(1,30)$. The main treatments for anti-NMDAR encephalitis are stepwise escalation of immunotherapy and tumor resection $(1,11)$. In this study, 24 patients $(61.5 \%)$ received first-line treatment and 15 patients (38.5\%) received firstline and second-line immunotherapies. Although the difference was not statistically significant, it seemed like more antiNMDAR encephalitis patients with systemic autoantibodies receiving second-line treatments than that without systemic autoantibodies. That finding was consistent with clinical features that consciousness disturbance was more prevalent in patients with systemic autoantibodies, though the difference of mRS at admission was not statistically significant.

We are aware that this study has some limitations. First, the sample size was relatively small. Second, we only detected systemic autoantibodies in the serum, not in the CSF, which result could strengthen our findings. Third, as a retrospective study, bias is inevitable.

In conclusion, our data demonstrated serum systemic autoantibodies were more frequent in anti-NMDAR encephalitis patients than in healthy controls and less frequent than NMOSD, which were associated with higher severity of disease.

\section{DATA AVAILABILITY STATEMENT}

The raw data supporting the conclusions of this article will be made available by the authors, without undue reservation, to any qualified researcher.

\section{ETHICS STATEMENT}

This study was approved by the Medical Ethics Committee of the Third Affiliated Hospital of Sun Yat-sen University. The need for obtaining written informed consent from patients or their family members was waived by the same committee.

\section{AUTHOR CONTRIBUTIONS}

BZ, YY, YL, and ZL designed the research. LA performed the experiments and analyzed the data. XM wrote the main manuscript text and prepared the figures. BZ edited and revised the manuscript. All authors reviewed and approved the manuscript.

\section{FUNDING}

This study was supported by the National Natural Science Foundation of China (81971110, 81671178); the Natural Science Foundation of Guangdong Province (2017A030311013); the Third Affiliated Hospital of Sun Yat-Sen University, Clinical Research Program (QHJH201907).

\section{SUPPLEMENTARY MATERIAL}

The Supplementary Material for this article can be found online at: https://www.frontiersin.org/articles/10.3389/fneur. 2020.00117/full\#supplementary-material

Supplementary Table 1 | Additional data of healthy controls. 


\section{REFERENCES}

1. Titulaer MJ, McCracken L, Gabilondo I, Armangue T, Glaser C, Iizuka T, et al. Treatment and prognostic factors for long-term outcome in patients with antiNMDA receptor encephalitis: an observational cohort study. Lancet Neurol. (2013) 12:157-65. doi: 10.1016/S1474-4422(12)70310-1

2. Florance NR, Davis RL, Lam C, Szperka C, Zhou L, Ahmad S, et al. Anti-N-methyl-D-aspartate receptor (NMDAR) encephalitis in children and adolescents. Ann Neurol. (2009) 66:11-8. doi: 10.1002/ana.21756

3. Pruss H, Finke C, Holtje M, Hofmann J, Klingbeil C, Probst C, et al. N-methylD-aspartate receptor antibodies in herpes simplex encephalitis. Ann Neurol. (2012) 72:902-11. doi: 10.1002/ana.23689

4. Scheer S, John RM. Anti-N-methyl-D-aspartate receptor encephalitis in children and adolescents. J Pediatr Health Care. (2016) 30:347-58. doi: 10.1016/j.pedhc.2015.09.004

5. Dobson R, Giovannoni G. Autoimmune disease in people with multiple sclerosis and their relatives: a systematic review and meta-analysis. J Neurol. (2013) 260:1272-85. doi: 10.1007/s00415-012-6790-1

6. Zhang B, Zhong Y, Wang Y, Dai Y, Qiu W, Zhang L, et al. Neuromyelitis optica spectrum disorders without and with autoimmune diseases. BMC Neurol. (2014) 14:162. doi: 10.1186/s12883-014-0162-7

7. Lin Y, Tan S, Wang Y, Shen X, Shu Y, Shan Y, et al. Anti-thyroid antibodies and thyroid function in anti-N-methyl-d-aspartate receptor encephalitis. Neurochem Int. (2018) 113:107-11. doi: 10.1016/j.neuint.2017.11.019

8. Ma X, Yin Q, Zeng Z, Wang C, Yang Y, Guo S. Thyroid function and autoimmune indications in patients with anti-N-methyl-D-aspartate receptor encephalitis. Neuroimmunomodulation. (2018) 25:110-7. doi: $10.1159 / 000492179$

9. Shu Y, Chen C, Chen Y, Xu Y, Chang Y, Li R, et al. Serum complement levels in anti-N-methyl-d-aspartate receptor encephalitis. Eur J Neurol. (2018) 25:178-84. doi: 10.1111/ene.13495

10. Lai M, Hughes EG, Peng X, Zhou L, Gleichman AJ, Shu H, et al. AMPA receptor antibodies in limbic encephalitis alter synaptic receptor location. Ann Neurol. (2009) 65:424-34. doi: 10.1002/ana.21589

11. Graus F, Titulaer MJ, Balu R, Benseler S, Bien CG, Cellucci T, et al. A clinical approach to diagnosis of autoimmune encephalitis. Lancet Neurol. (2016) 15:391-404. doi: 10.1016/S1474-4422(15)00401-9

12. Wingerchuk DM, Banwell B, Bennett JL, Cabre P, Carroll W, Chitnis $\mathrm{T}$, et al. International consensus diagnostic criteria for neuromyelitis optica spectrum disorders. Neurology. (2015) 85:177-89. doi: 10.1212/WNL.0000000000001729

13. Sinha AA, Lopez MT, McDevitt HO. Autoimmune diseases: the failure of self tolerance. Science. (1990) 248:1380-8. doi: 10.1126/science. 1972595

14. Jacome Sanchez EC, Garcia Castillo MA, Gonzalez VP, Guillen Lopez F, Correa Diaz EP. Coexistence of systemic lupus erythematosus and multiple sclerosis. A case report and literature review. Mult Scler J Exp Transl Clin. (2018) 4:2055217318768330. doi: 10.1177/2055217318768330

15. Zhao J, Wang C, Xu X, Zhang Y, Ren H, Ren Z, et al. Coexistence of autoimmune encephalitis and other systemic autoimmune diseases. Front Neurol. (2019) 10:1142. doi: 10.3389/fneur.2019.01142

16. Nifli AP, Notas G, Mamoulaki M, Niniraki M, Ampartzaki V, Theodoropoulos $\mathrm{PA}$, et al. Comparison of a multiplex, bead-based fluorescent assay and immunofluorescence methods for the detection of ANA and ANCA autoantibodies in human serum. J Immunol Methods. (2006) 311:189-97. doi: 10.1016/j.jim.2006.02.004

17. Guo YP, Wang CG, Liu X, Huang YQ, Guo DL, Jing XZ, et al. The prevalence of antinuclear antibodies in the general population of china: a cross-sectional study. Curr Ther Res Clin Exp. (2014) 76:116-9. doi: 10.1016/j.curtheres.2014.06.004
18. Wananukul S, Voramethkul W, Kaewopas Y, Hanvivatvong O. Prevalence of positive antinuclear antibodies in healthy children. Asian Pac J Allergy Immunol. (2005) 23:153-7.

19. Sur LM, Floca E, Sur DG, Colceriu MC, Samasca G, Sur G. Antinuclear antibodies: marker of diagnosis and evolution in autoimmune diseases. Lab Med. (2018) 49:e62-73. doi: 10.1093/labmed/lmy024

20. Satoh M, Chan EK, Ho LA, Rose KM, Parks CG, Cohn RD, et al. Prevalence and sociodemographic correlates of antinuclear antibodies in the United States. Arthritis Rheum. (2012) 64:2319-27. doi: 10.1002/art. 34380

21. Zhernakova A, Withoff S, Wijmenga C. Clinical implications of shared genetics and pathogenesis in autoimmune diseases. Nat Rev Endocrinol. (2013) 9:646-59. doi: 10.1038/nrendo.2013.161

22. Matzaraki V, Kumar V, Wijmenga C, Zhernakova A. The MHC locus and genetic susceptibility to autoimmune and infectious diseases. Genome Biol. (2017) 18:76. doi: 10.1186/s13059-017-1207-1

23. Shu Y, Qiu W, Zheng J, Sun X, Yin J, Yang X, et al. HLA class II allele DRB1*16:02 is associated with anti-NMDAR encephalitis. $J$ Neurol Neurosurg Psychiatry. (2019) 90:652-8. doi: 10.1136/jnnp-2018-3 19714

24. Mueller SH, Farber A, Pruss H, Melzer N, Golombeck KS, Kumpfel T, et al. Genetic predisposition in anti-LGI1 and anti-NMDA receptor encephalitis. Ann Neurol. (2018) 83:863-9. doi: 10.1002/ana.25216

25. Hirohata S, Sakuma Y, Matsueda Y, Arinuma Y, Yanagida T. Role of serum autoantibodies in blood brain barrier damages in neuropsychiatric systemic lupus erythematosus. Clin Exp Rheumatol. (2018) 36:1003-7.

26. Fragoso-Loyo H, Cabiedes J, Orozco-Narvaez A, Davila-Maldonado L, Atisha-Fregoso Y, Diamond B, et al. Serum and cerebrospinal fluid autoantibodies in patients with neuropsychiatric lupus erythematosus. Implications for diagnosis and pathogenesis. PLOS ONE. (2008) 3:e3347. doi: 10.1371/journal.pone.0003347

27. Lungen EM, Maier V, Venhoff N, Salzer U, Dersch R, Berger B, et al. Systemic lupus erythematosus with isolated psychiatric symptoms and antinuclear antibody detection in the cerebrospinal fluid. Front Psychiatry. (2019) 10:226. doi: 10.3389/fpsyt.2019.00226

28. Finke C, Bartels F, Lutt A, Pruss H, Harms L. High prevalence of neuronal surface autoantibodies associated with cognitive deficits in cancer patients. J Neurol. (2017) 264:1968-77. doi: 10.1007/s00415-0178582-0

29. Zerche M, Weissenborn K, Ott C, Dere E, Asif AR, Worthmann H, et al. Preexisting serum autoantibodies against the NMDAR subunit NR1 modulate evolution of lesion size in acute ischemic stroke. Stroke. (2015) 46:1180-6. doi: 10.1161/STROKEAHA.114.008323

30. Sonderen AV, Arends S, Tavy DLJ, Bastiaansen AEM, Bruijn M, Schreurs MWJ, et al. Predictive value of electroencephalography in anti-NMDA receptor encephalitis. J Neurol Neurosurg Psychiatry. (2018) 89:1101-6. doi: 10.1136/jnnp-2018-318376

Conflict of Interest: The authors declare that the research was conducted in the absence of any commercial or financial relationships that could be construed as a potential conflict of interest.

Copyright (c) 2020 Zhang, Yang, Lin, Ai, Men and Lu. This is an open-access article distributed under the terms of the Creative Commons Attribution License (CC BY). The use, distribution or reproduction in other forums is permitted, provided the original author(s) and the copyright owner(s) are credited and that the original publication in this journal is cited, in accordance with accepted academic practice. No use, distribution or reproduction is permitted which does not comply with these terms. 